\title{
Analisis Potensi Biomassa Limbah Pabrik Kelapa Sawit (PKS) Untuk Pembangkitan Energi Listrik Di Kabupaten Landak Provinsi KalimantanBarat
}

\author{
Yohannes M. Simanjuntak ${ }^{1)}$, Danial ${ }^{2)}$, M. Taufiqurrahman ${ }^{3)}$, Eddy Kurniawan ${ }^{4)}$ \\ ${ }^{1,2)}$ Program Studi Teknik Elektro, \\ ${ }^{3,4)}$ Program Studi Teknik Mesin Jurusan Teknik Elektro, \\ Fakultas Teknik, Universitas Tanjungpura \\ e-mail : yohanes_john56@yahoo.com
}

\begin{abstract}
The potency of palm oil mills (PKS) biomass in Kabupaten Landak have been evaluated as alternative for electrical energy in that area. The results have shown that solid biomass (empty fruit bunchs and shells) produced by those of PKS in 2016 have significant potency for generating electrical power. By using steam turbine technology, the biomass potency equal to 2 units of $13 \mathrm{MW}$ power plant.
\end{abstract}

Keywords-Biomass, empty fruit bunch, shell, alternative energy, Landak

\section{Pendahuluan}

Luas areal perkebunan sawit di Kabupaten Landak mencapai 106.695 hektar, perkebunan terbesarnya berada di Kecamatan Ngabang. Selain menghasilkan CPO dan inti sawit sebagai produk utama dari pengolahan TBS (tandanbuah segar), juga dihasilkan limbah berbentuk padat dan cair. Limbah padatterdiri dari serat (fiber), cangkang (shell) dan TKS (tandan kosong sawit), sedangkan limbah cair, yang sering disebut palm oil mill effluent atau POME, berupa sisa minyak dan lumpur. Serat dan sebagian dari cangkang digunakansebagai bahan bakar boiler untuk proses pengolahan TBS, sisa cangkang dijualdi pasar lokal sedangkan TKS sebagian dimanfaatkan sebagai pupuk atau dibakar di incenerator. Limbah cair ada yang memanfaatkannya sebagai pupukatau diproses secara mikro organisme sebelum dilepas ke pembuangan akhir.

TKS dalam jumlah besar sering menimbulkan permasalahan dan cukup merepotkan, dibakar menggangu lingkungan, asap yang dihasilkan menimbulkanpencemaran udara berlebihan, sedangkan dibuat pupuk organik kurang ekonomis. TKS memiliki kandungan energi yang setara dengan serabut bilamana dikeringkan hingga kandungan air didalamnya (MC) mencapai kurang dari40\%. Proses pengolahan TKS dapat dilakukan dengan beberapa metode dantahapan, salah satunya adalah dengan dicacah, dipres, kemudian dikeringkan dengan dryer. Metode lainnya adalah dengan memasukkan TKS ke dalammesin grinder-dryer. TKS yang telah dikeringkan dan diperkecil ukurannya dicampur dengan cangkang dapat digunakan sebagai bahan bakar boiler untuk pembangkit tenaga listrik.
Biomassa limbah PKS (pabrik kelapa sawit) yang sangat melimpah, terutamaTKS, dapat dimanfaatkan sebagai salah satu energi alternatif untuk pembangkitan energi listrik. Oleh karena kandungan air pada TKS relatif tinggi (MC60\%) maka diperlukan teknologi yang tepat untuk memanfaatkannya sebagaisumber energi listrik. Proses konversi energi biomassa menjadi listrik dapatmenggunakan teknologi gasifikasi atau pembakaran langsung, namun keduanya memiliki persyaratan yang sama, yaitu kandungan air biomassa tidak bolehlebih dari $40 \%$.

Dalam upaya memberikan nilai tambah terhadap biomassa limbah PKS (terutama TKS dan cangkang) bagi peningkatan kesejahteraan masyarakat, makadilakukan studi potensi biomassa limbah PKS menjadi energi listrik.

\section{Limbah Sawit}

Secara rata-rata, pada setiap PKS, untuk 1 ton TBS akan dihasilkan limbah sawit sebagai berikut.

- Limbah padat, meliputi

- TKS sekitar $23 \%$

- Serat sekitar $13 \%$

- Cangkang sekitar 5,5\%

- Wet decanter solid sekitar $4 \%$

- Abu boiler sekitar 50\%

- Limbah cair, sekitar 50\%

Pemanfaatan limbah padat (cangkang dan serabut) sebagai bahan-bakar sudah dilakukan pada boiler (keteluap) di PKS untuk menghasilkan uap air untuk kebutuhan proses pabrik, dan membangkitkan listrik untuk kebutuhan pabrik dan perumahan pegawai di sekitar PKS. Karena karakteristiknya berbeda, TKS tidak dapat digunakan sebagai sumber energi secara langsung denganmenggunakan fasilitas yang sama dengan cangkang dan serabut [1].

TKS diketahui mempunyai kandungan air yang sangat tinggi, sekitar 50 persen sampai 60 persen, dan mengandung potassium $(\mathrm{K})$ yang mencapai 2,4 persen, selain itu diketahui juga mengandung klorin $(\mathrm{Cl})[1]$. Efek korosi akan meningkat dengan meningkatnya kandungan $\mathrm{Cl}$, dan unsur potassium dapat berperan 
dalam pembentukan deposit pada superheater yang dapat menggangguproses pemindahan panas di tungku bakar.

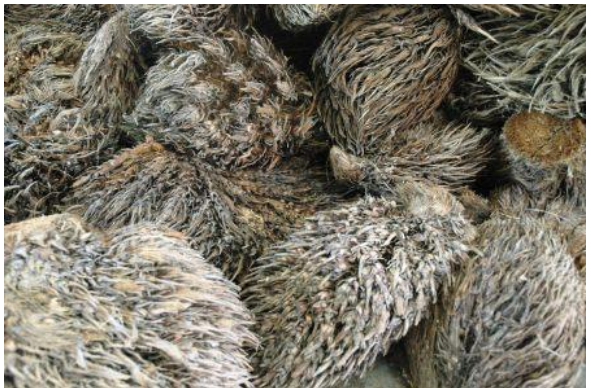

Gambar 1. Tandan kosong sawit (TKS)

Karakteristik yang berbeda dari TKS menyebabkan dibutuhkannya teknologi yang khusus dalam pemanfaatannya sebagai bahan-bakar. Pada prinsipnya, untuk meningkatkan efisiensi pembakaran, kandungan air TKS harus dikurangi sampai sekitar 40 persen dan efek dari unsur alkali harus diatasi. [1]

Unsur-unsur penting yang mempengaruhi nilai kalori pada tanaman kelapa sawit ditunjukkan dalam Tabel 1. Tingginya unsur $\mathrm{C}$ dan $\mathrm{O}$ akan sangat berpengaruh terhadap tingginya nilai kalori dari biomassa tersebut. Selain kandungan unsur dalam material biomassa, nilai kalori juga dipengaruhi oleh besarnyakandungan air atau tingkat kekeringan dari bahan biomassa. Hubungan antara nilai kalori dan kandungan air pada TKS ditunjukkan dalam Gambar 2dan 3. Pada Gambar 2 dan 3, TKS dibagi menjadi dua jenis, yaitu TKS yangmengandung minyak (oily) dan yang sudah tidak mengandung minyak (pure).

Kedua jenis TKS ini mempunyai nilai kalor yang berbanding terbalik dengan kandungan kadar air, dimana nilai kalor akan naik apabila kadar air TKSberkurang, dan pada saat bersamaan jumlah massa TKS juga berkurang akibathilangnya sebagian kandungan air dari TKS. Persamaan empiris yang menghubungkan antara nilai kalor dan kandungan air pada kedua jenis TKS ini ditunjukkan oleh kedua persamaan berikut. [1] Untuk TKS yang mengandungminyak (oily EFB),

$$
y=-213,47 x+18836
$$

Untuk TKS kering (pure EFB)

$$
y=-202,07 x+17563
$$

Dalam persamaan ini, $x$ adalah kadar air dalam persen (\%) dan dalam persen (\%) dan y adalah nilai kalor dalam $\mathrm{kJ} / \mathrm{kg}$.

Untuk menghitung massa TKS setelah diturunkan kandungan airnya darikondisi sebelumnya digunakan formulasi berikut. Jika pada saat keluar dariproses pengolahan, TKS memiliki kandungan air (MC) 60\%, berarti setiap $1 \mathrm{kgTKS}$ mengandung $0,6 \mathrm{~kg}$ air dan 0,4 $\mathrm{kg}$ biomassa. Dan, jika TKS tersebut inginditurunkan kandungan airnya menjadi $45 \%$, maka massa TKS pada MC 45\%dapat dihitung sebagai berikut:

$$
0,45=x /(0,4+X)
$$

didapat $X=0,33$. Massa TKS pada MC $45 \%=0,4+0$, $33=0,73 \mathrm{~kg}$. Massa tersebut yang digunakan sebagai dasar perhitungan untuk menentukan besarnya nilai kalori dari TKS selanjutnya.

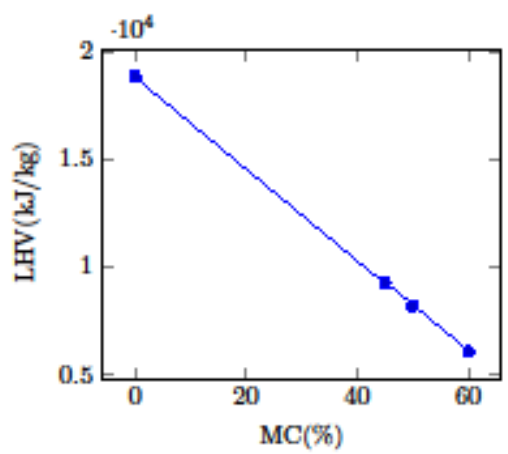

Gambar 2. Oily EFB

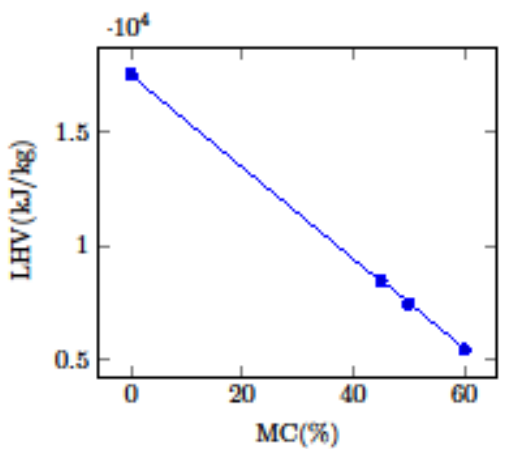

Gambar 3. Pure EFB

Tabel 1. Kandungan unsur kimia pembentuk kalor pada tanaman kelapa sawit (dalam persen)

\begin{tabular}{cccc}
\hline Elemen & TKS & Batang & Pelepah \\
\hline \hline $\mathrm{C}$ & 53,78 & 40,64 & 52,28 \\
\hline $\mathrm{H}$ & 4,37 & 5,09 & - \\
\hline $\mathrm{O}$ & 41,50 & 53,12 & - \\
\hline $\mathrm{N}$ & 0,35 & 2,15 & 0,75 \\
\hline $\mathrm{S}$ & - & - & - \\
\hline $\begin{array}{c}\mathrm{CV} \\
\mathrm{MJ} / \mathrm{kg})\end{array}$ & 17,08 & 17,27 & - \\
\hline
\end{tabular}

Selain TKS, limbah pabrik minyak sawit yang dapat digunakan sebagai bahan bakar boiler adalah cangkang atau shell. Rata-rata limbah cangkang yangdihasilkan dari proses pengolahan TBS adalah sebesar 5\%. Cangkang memilikinilai kalori yang lebih tinggi dari TKS, yaitu sekitar $18 \mathrm{MJ} / \mathrm{kg}$ pada MC 30\%.Berbeda dengan TKS, cangkang tidak memerlukan perlakuan awal untuk dijadikan bahan bakar di dalam boiler. Untuk proses pengolahan minyak sawitumumnya bahan bakar yang digunakan tidak cukup hanya menggunakan serat(fiber), sehingga memerlukan tambahan sedikit cangkang. Volume cangkang sisa dari proses 
pengolahan minyak sawit yang tidak digunakan berkisar antara $3 \%$.

Untuk PKS yang menggunakan boiler berefisiensi tinggi biasanya cukupmenggunakan bahan bakar dari serat saja. Penggunaan bahan bakar cangkang sebagai campuran serat dalam jumlah banyak akan menimbulkan kerak(clinker) di dalam tungku. Timbulnya clinker di dalam tungku merupakan permasalahan yang harus menjadi perhatian secara terus-menerus, karena dapatmenggangu proses pembakaran, terutama untuk boiler yang tidak dilengkapidengan travelling grate. Volume clinker yang besar akan mempersempit ruangpembakaran, sehingga harus dilakukan pembersihan secara rutin dan sebagaidampaknya kontinyuitas produksi uap akan terganggu. Pada sistem pembangkit listrik yang memerlukan kontinyuitas pelayanan yang tinggi, pemilihan jenis boiler yang tepat merupakan kunci sukses dari operasional power plant.

Selain limbah padat, PKS juga menghasilkan limbah cair (POME) yang dapat menimbulkan dampak negatif bagi lingkungan karena memiliki kandungan Biochemical Oxygen Demand (BOD) dan Chemical Oxygen Demand (COD)yang sangat tinggi. Sebelum dilepas ke saluran pembuangan, limbah cair PKStidak boleh mengandung BOD lebih dari $250 \mathrm{mg} / \mathrm{l}$ dan COD lebih dari 500mg/l. Untuk menurunkan kandungan BOD dan COD tersebut PKS membangun kolam pengolahan limbah yang terdiri dari 8-10 kolam, dimana 2 kolampertama merupakan kolam an-aerobic dan sisanya merupakan kolam aerobic.

Limbah cair ini rata-rata didesain dengan waktu tinggal sekitar 25-30 hariuntuk setiap kolam. Jika melebihi waktu, maka volume air akan melebihi dayatampung kolam, sehingga air meluber ke kolam sebelahnya. Rata-rata desainkedalaman kolam adalah 56 meter. Tetapi pada kenyataannya pendangkalanterjadi lebih cepat, sehingga kedalaman rata rata hanya 2-3 m. Pendangkalanini sebenarnya menganggu proses anaerobic, dan proses terbentuknya gas metana $\left(\mathrm{CH}_{4}\right)$. Gas ini secara kasat mata dapat dilihat dalam bentuk gelembung-gelembung yang timbul di permukaan kolam, apabila terkumpul dalam konsentrasi yang cukup tinggi dapat menimbulkan kebakaran dan efek pemanasanglobal. Efek pemanasan global yang ditimbulkan oleh gas metana empat kalilebih besar dari gas $\mathrm{CO}_{2}$.

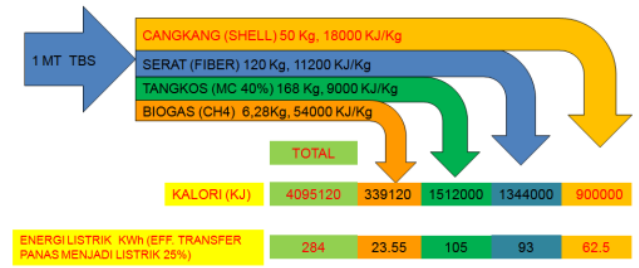

Gambar 4. Volume dan nilai kalori limbah PKS

Besarnya kalori yang terkandung dalam limbah hasil pengolahan TBS danenergi listrik yang dapat dibangkitkan dari pemanfaatan limbah tersebut ditunjukkan dalam Gambar 4. Dari hasil pengolahan 1 (satu) metrik ton TBS akanmenghasilkan limbah padat dan cair yang memiliki potensi untuk menghasilkan energi listrik sebesar $284 \mathrm{kWh}$, dengan asumsi efisiensi konversi energi panasmenjadi listrik sebesar $25 \%$.

\section{Hasil Eksperimen}

\subsection{Potensi Biomassa Sawit}

Jumlah perusahaan perkebunan sawit yang memegang IUP di Kabupaten Landak mencapai 46 perusahaan dengan luas lahan sebesar 444.814 hektar. LokasiIUP tersebar di seluruh kabupaten, yang terbanyak berada di Kecamatan Ngabang dan Kuala Behe. Luas lahan realisasi tanam adalah 116.815 ha dengan intisebesar 92.434 ha dan plasma sebesar 24.381 ha. [2]

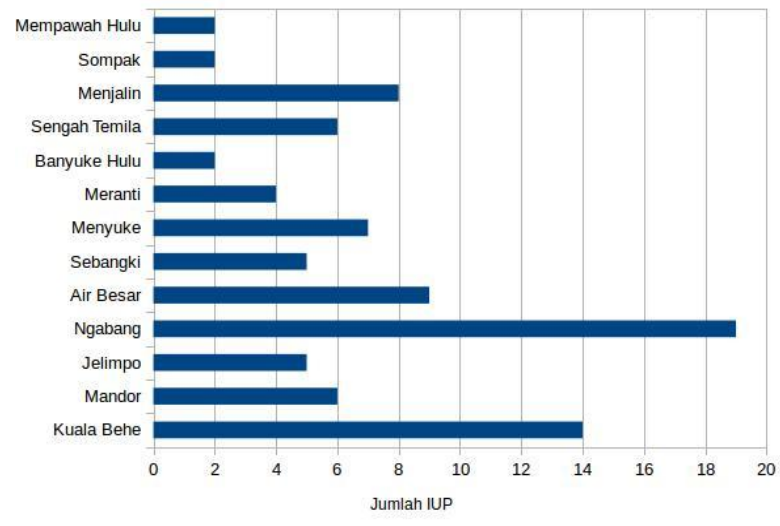

Gambar 5. Lokasi IUP di Kabupaten Landak.[2]

Tabel 2. Potensi biomassa sawit [2]

\begin{tabular}{clccc}
\multicolumn{6}{c}{ Tabel 2. Potensi biomassa sawit [2] } \\
\hline \multirow{2}{*}{ No } & \multicolumn{1}{c}{$\boldsymbol{P K S}$} & $\begin{array}{c}\text { Produksi } \\
\text { (ton/jam) }\end{array}$ & $\begin{array}{c}\text { TKS } \\
\text { (ton/jam) }\end{array}$ & $\begin{array}{c}\text { Cangkang } \\
\text { (ton/jam) }\end{array}$ \\
\hline \hline 1 & PT.SMS & 60 & 13,8 & 3,6 \\
\hline 2 & $\begin{array}{l}\text { PTPN } \\
\text { XIII }\end{array}$ & 45 & 10,35 & 2,7 \\
\hline 3 & PT.MPS & 30 & 6,9 & 1,8 \\
\hline 4 & PT.IGP & 60 & 13,8 & 3,6 \\
\hline 5 & PT.KRS & 60 & 13,8 & 3,6 \\
\hline 6 & PT.ANI & 45 & 10,35 & 2,7 \\
\hline & & 300 & 69 & 18 \\
\hline
\end{tabular}

Sampai tahun 2015, terdapat 6 pabrik kelapa sawit (PKS) di KabupatenLandak dengan total produksi sebesar 300 ton TBS/jam[2]. Produksi masing-masing PKS ditunjukkan pada Tabel 2. Perusahaan tersebut adalah PT. SatriaMulti Sukses (SMS), PT. Perkebunan Nusantara XIII (PTPN XIII), PT. Multi Perkasa Sejahtera (MPS), PT. Ichtiar Gusti Pudi (IGP), PT. Kapuas Rimba Sejahtera(KRS), dan PT. Agro Nusa Investama (ANI).

Jumlah TKS dan cangkang pada Tabel 3.1 dihitung berdasarkan hasil perhitungan LaCrosse (2004). Apabila jam operasi setiap PKS adalah 20 jam perhari dan beroperasi selama 285 hari per tahun[2], maka potensi limbah sawit diKabupaten Landak adalah seperti diberikan pada Tabel 3. 
Tabel 3. Potensi limbah biomassa sawit per tahun

\begin{tabular}{clc}
\hline No & Limbah PKS & Jumlah limbah (ton/tahun) \\
\hline 1 & TKS & 393.300 \\
\hline 2 & Cangkang & 102.600 \\
\hline
\end{tabular}

\subsection{Analisa Kebutuhan Bahan Bakar Power Plant}

Untuk menghitung besarnya volume bahan bakar cangkang dan TKS yang dibutuhkan oleh power plant, diperlukan data mengenai sistem boiler sebagaiperalatan pengubah kalor menjadi tenaga uap dan data mengenai turbin generator sebagai pengubah tenaga uap menjadi tenaga listrik. Untuk itu diambilasumsi sebagai berikut.

1) Power plant direncanakan beroperasi selama 7008 jam per tahun (abitity factor $80 \%$ ) dan memasok energi listrik ke jaringan PLN minimal sebesar $80 \%$ (capability factor $80 \%$ ) dari kapasitas terpasang (penggunaan energi listrik untuk memenuhi kebutuhan operasional power plant diperkirakan sebesar 10\%-15\% dari kapasitas terpasang).

2) Power plant direncanakan memiliki kemampuan untuk memasok energi listrik ke jaringan PLN sebesar $10 \mathrm{MWe}$, maka power plant harus memiliki kemampuan daya terpasang minimal sebesar 13 MWe.

Spesifikasi komponen boiler dan turbin generator untuk power plant adalahsebagai berikut.

1) Data boiler
a. Jenis boiler: superheated
b. Efisiensi: $80 \%$
c. Kapasitas: 35 ton uap/jam
d. Tekanan kerja: $40 \mathrm{~kg} / \mathrm{cm}^{2}$
e. Temperatur uap: $400^{\circ} \mathrm{C}$
f. Suhu air umpan: $100^{\circ} \mathrm{C}$

Dari data tersebut, pada tabel uap diperoleh karakteristik berikut.

Entalphy uap: $3.214,1 \mathrm{~kJ} / \mathrm{kg}$

Enthalphy air umpan: $419 \mathrm{~kJ} / \mathrm{kg}$

Delta entalphy antara air umpan dan uap adalah sebesar $2.795,1 \mathrm{~kJ} / \mathrm{kg}$.

2) Data turbin
a. Tipe: multi-stage condensing
b. Tekanan uap masuk: $40 \mathrm{~kg} / \mathrm{cm}^{2}$
c. Temperatur: $400^{\circ} \mathrm{C}$
d. Efisiensi: $70 \%$
e. Tekanan uap keluar: $0,1 \mathrm{~kg} / \mathrm{cm}^{2}$
f. Temperatur air keluar: $46^{\circ} \mathrm{C}$

Data dari turbin tersebut, pada tabel uap diperoleh karakteristik berikut.

Entalphy uap masuk: $3.214,1 \mathrm{kj} / \mathrm{kg}$

Entalphy uap keluar: $2.465,2 \mathrm{~kJ} / \mathrm{kg}$

Delta entalphy antara uap masuk dan uap keluar turbin adalah sebesar 748,9 kJ/kg.

Konsumsi uap untuk menghasilkan energi listrik/kWh dapat dicari denganmenghitung hasil bagi $(3.600 \mathrm{~kJ} / \mathrm{kWh})$ dan $(748,9 \mathrm{~kJ} / \mathrm{kg})$, yaitu 4,8 $\mathrm{kg}$ per $\mathrm{kWh}$.

Untuk memproduksi $1 \mathrm{~kg}$ uap dari $100^{\circ} \mathrm{C}$ menjadi $400 \circ \mathrm{C}$ pada tekanan $40 \mathrm{~kg} / \mathrm{cm}^{2}$, jika menggunakan bahan bakar campuran TKS MC 40\% dengan nilaikalori 9.000 $\mathrm{kJ} / \mathrm{kg}$ dan cangkang dengan nilai kalori $18.000 \mathrm{~kJ} / \mathrm{kg}$ pada efisiensi boiler $80 \%$, maka jumlah bahan bakar TKS dan cangkang yang dibutuhkanadalah sbb:

TKS $=(2795,1 / 9000) / 0,8=0,3882 \mathrm{~kg}$

Cangkang $=(2795,1 / 18000) / 0,8=0,1941 \mathrm{~kg}$

Karena untuk menghasilkan energi listrik $1 \mathrm{kWh}$ diperlukan uap sebesar $4,8 \mathrm{~kg}$ uap pada tekanan 40 $\mathrm{kg} / \mathrm{cm}^{2}$ dan temperatur $400^{\circ} \mathrm{C}$, maka besar bahan bakaryang diperlukan untuk setiap $1 \mathrm{kWh}$ adalah

TKS $=0,3875 \times 4,8=1,86 \mathrm{~kg}$ pada MC $40 \%$, atau

TKS $=2,52 \mathrm{~kg}$ pada $\mathrm{MC} 60 \%$, atau

Cangkang $=0,194 \times 4,8=0,93 \mathrm{~kg}$

Kebutuhan bahan bakar power plant dengan berbagai komposisi campuranTKS MC $60 \%$ dan cangkang MC $30 \%$, ditunjukkan pada Tabel 4. Kebutuhanbahan bakar per tahun pada $\mathrm{AF}=80 \%$ (7008 jam) ditunjukkan pada Tabel 5.

Tabel 4. Kebutuhan bahan-bakar TKS (MC 60\%) dan cangkang (MC 30\%) pada berbagai komposisi campuran dan daya keluaran rata-rata per jam

\begin{tabular}{|c|c|c|c|c|c|c|c|c|}
\hline \multirow{4}{*}{$\begin{array}{c}\text { Kapasitas } \\
\text { Daya } \\
\text { Rata-rata } \\
(\mathrm{kW})\end{array}$} & \multicolumn{8}{|c|}{ Massa bahan-bakar dg berbagai komposisi (ton) } \\
\hline & \multicolumn{2}{|c|}{$\begin{array}{c}\text { TKS \& } \\
\text { Cangkang }\end{array}$} & \multicolumn{2}{|c|}{$\begin{array}{c}\text { TKS \& } \\
\text { Cangkang }\end{array}$} & \multicolumn{2}{|c|}{$\begin{array}{c}\text { TKS \& } \\
\text { Cangkang }\end{array}$} & \multirow{3}{*}{$\begin{array}{c}T K \\
S \\
100 \\
\%\end{array}$} & \multirow{3}{*}{$\begin{array}{c}\text { Can } \\
\text { gka } \\
n g \\
100 \\
\%\end{array}$} \\
\hline & 80 & 20 & 85 & 15 & 90 & 10 & & \\
\hline & $\%$ & $\%$ & $\%$ & $\%$ & $\%$ & $\%$ & & \\
\hline \multirow{2}{*}{10.000} & 16 , & 3,1 & 18, & 2,4 & 20 & 1,6 & 25 & 9,3 \\
\hline & 744 & 01 & 558 & 26 & 542 & 91 & 111 & 02 \\
\hline \multirow{2}{*}{11.000} & 18 & 3,4 & 20 , & 2,6 & 22 & 1,8 & 27, & 10 \\
\hline & 418 & 11 & 414 & 69 & 595 & 60 & 622 & 233 \\
\hline \multirow{2}{*}{12.000} & 20 , & 3,7 & 22, & 2,9 & 24, & 2,0 & 30, & 11, \\
\hline & 093 & 21 & 270 & 11 & 650 & 29 & 133 & 163 \\
\hline \multirow{2}{*}{12.500} & 20, & 3,8 & 23, & 3,0 & 25 , & 2,1 & 31, & 11, \\
\hline & 930 & 76 & 198 & 33 & 676 & 13 & 388 & 628 \\
\hline \multirow{2}{*}{13.000} & 21, & 4,0 & 24, & 3,1 & 26 , & 2,1 & 32 , & 12, \\
\hline & 767 & 31 & 127 & 54 & 703 & 98 & 645 & 093 \\
\hline \multirow{2}{*}{13.500} & 22, & 4,1 & 25 , & 3,2 & 27 , & 2,2 & 33, & 12, \\
\hline & 604 & 86 & 054 & 75 & 730 & 82 & 901 & 558 \\
\hline
\end{tabular}

Tabel 5. Kebutuhan bahan bakar TKS (MC 60\%) dan cangkang (MC 30\%)pada berbagai komposisi campuran per tahun

\begin{tabular}{|c|c|c|c|c|c|c|c|c|}
\hline \multirow{4}{*}{$\begin{array}{c}\text { Kapasitas } \\
\text { Daya } \\
\text { Rata-rata } \\
\quad(k W)\end{array}$} & \multicolumn{8}{|c|}{ Massa bahan-bakar dg berbagai komposisi (ton) } \\
\hline & \multicolumn{2}{|c|}{$\begin{array}{c}\text { TKS \& } \\
\text { Cangkang }\end{array}$} & \multicolumn{2}{|c|}{$\begin{array}{c}\text { TKS \& } \\
\text { Cangkang }\end{array}$} & \multicolumn{2}{|c|}{$\begin{array}{c}\text { TKS \& } \\
\text { Cangkang }\end{array}$} & \multirow{2}{*}{$\begin{array}{c}T K \\
S \\
100\end{array}$} & \multirow{2}{*}{$\begin{array}{c}\text { Can } \\
\text { gka } \\
\text { ng } \\
100\end{array}$} \\
\hline & 80 & 20 & 85 & 15 & 90 & 10 & & \\
\hline & $\%$ & $\%$ & $\%$ & $\%$ & $\%$ & $\%$ & $\%$ & $\%$ \\
\hline \multirow{3}{*}{10.000} & 1117 & 21. & 130 & 17. & 143 & 11. & 175 & 65. \\
\hline & .34 & 732 & .05 & 001 & .95 & 851 & .98 & 188 \\
\hline & 2 & & 8 & & 6 & & 0 & \\
\hline \multirow{3}{*}{11.000} & 129 & 23. & 143 & 18. & 158 & 13. & 193 & 71. \\
\hline & .07 & 904 & .06 & 704 & .34 & 035 & .57 & 713 \\
\hline & 4 & & 6 & & 5 & & 7 & \\
\hline \multirow{3}{*}{12.000} & 140 & 26. & 156 & 20. & 172 & 14. & 211 & 78. \\
\hline & .81 & 077 & .07 & 400 & .74 & 219 & .17 & 230 \\
\hline & 5 & & 5 & & 5 & & 5 & \\
\hline \multirow{3}{*}{12.500} & 146 & 27. & 162 & 21. & 179 & 14. & 219 & 81. \\
\hline & .68 & 163 & .57 & 255 & .93 & 808 & .97 & 489 \\
\hline & 0 & & 4 & & 5 & & 3 & \\
\hline \multirow{3}{*}{13.000} & 152 & 28. & 169 & 22. & 187 & 15. & 228 & 84. \\
\hline & .54 & 249 & .08 & 103 & .13 & 404 & .78 & 748 \\
\hline & 6 & & 3 & & 5 & & 1 & \\
\hline \multirow{3}{*}{13.500} & 158 & 29. & 175 & 22. & 194 & 15. & 237 & 88. \\
\hline & .41 & 335 & .58 & 951 & .33 & 992 & .58 & 006 \\
\hline & 2 & & 3 & & 4 & & 0 & \\
\hline
\end{tabular}


Dengan menganalisa kebutuhan dan ketersediaan bahan bakar seperti tercantum dalam Tabel 5 dan 3, maka power plant sebesar 13 MW dapat mempergunakan biomassa sawit dengan berbagai komposisi,baik cangkang $100 \%$ atau TKS $100 \%$, ataupun komposisi lain seperti diberikan pada Tabel 5. Maksimum dua buah power plant dapat dibangun denganmenggunakan bahan bakar cangkang dan TKS.

\section{Kesimpulan}

Kesimpulan hasil penelitian adalah sebagai berikut.

1) Potensi TKS dan cangkang dari PKS yang ada di Kabupaten Landak mampu memenuhi kebutuhan bahan bakar power plant dengan kapasitas $2 \times 13$ MW.

2) Dengan operasi power plant per tahun selama 7008 jam, setiap power plant sebesar $13 \mathrm{MW}$ memerlukan bahan bakar 228.781 ton TKS per tahun atau 84.748 ton cangkang per tahun.

\section{Referensi}

[1] Irhan Febijanto. "Kajian Teknis \& Keekonomian Pembangkit Listrik Tenaga Biomassa Sawit Pinang Tinggi Sei Bahar Jambi.' Jurnal Mechatronics, Electrical Power, and Vehicular Technology, 2011.

[2] BPS Kabupaten Landak. "Kabupaten Landak Dalam Angka," 2016.

[3] Jarman. 'Electricity Program and Breakthrough Policies Towards Achieving New Renewable Energy and Energy Conservation Target in National Energy Policies.' Directorate General of Electricity. 2014.

[4] PLN. 'Rencana Usaha Penyediaan Tenaga Listrik (RUPTL) 2015 - 2024.’' 2015.

\section{Biography}

Yohannes M. Simanjuntak, adalah dosen tetap pada Program Studi Teknik Elektro Fakultas Teknik Universitas Tanjungpura, Pontianak. Lahir di Ketapang, tanggal 30 Januari 1956. S1 diperoleh tahun 1985 bidang ilmu Teknik Tenaga Listrik, S2 tahun 2009 bidang ilmu Manajemen Energi pada Fakultas Teknik Universitas Tanjungpura. (yohanes_john56@yahoo.com)

Danial, adalah dosen tetap pada Program Studi Teknik Elektro Fakultas Teknik Universitas Tanjungpura, Pontianak. Lahir di Sambas, tanggal 12 Pebruari 1962. S1 diperoleh tahun 1991 bidang ilmu Teknik Elektro pada Fakultas Teknik Universitas Tanjungpura, S2 tahun 1995 bidang ilmu Elektroteknik pada Institut Teknologi Bandung. (danial.noah@ee.untan.ac.id)

M. Taufiqurrahman, adalah dosen tetap pada Program Studi Teknik Mesin Fakultas Teknik Universitas Tanjungpura, Pontianak. Lahir di Pontianak, tanggal 3Juni 1982. S1 diperoleh tahun 2005 bidang studi Teknik Elektro pada Fakultas Teknik Universitas Tanjungpura, S2 tahun 2011bidang studi Teknik Mesin pada Universitas Brawijaya. (hwelex@gmail.com)

Eddy Kurniawan, adalah dosen tetap pada Program Studi Teknik Mesin Fakultas Teknik Universitas Tanjungpura, Pontianak. Lahir di Pontianak, tanggal 26 Desember 1984. S1 diperoleh tahun 2009 bidang ilmu Teknik Mesin pada Universitas Gajah Mada, S2 tahun 2013 bidang ilmu Teknik Industri pada Universitas Gajah Mada. (eddy_ugm@yahoo.com) 